\title{
Juan Fernández de Heredia y Plutarco. \\ Las Vidas Paralelas
}

Manuel Cerezo Magán

Universitat de Lleida

\section{La personalidad de Plutarco}

\subsection{Algunos datos biográficos}

Mi disertación va a tratar fundamentalmente de las Vidas Paralelas de Plutarco y de la traducción de éstas promovida por Juan Fernández de Heredia, Gran Maestre de la Orden de San Juan de Jerusalén en el siglo XIV, si bien tocaré por razones obvias otras cuestiones que nos van a ayudar a ponernos en situación. Empezaré por decir algunas cosas sobre Plutarco y su vida, aunque sea muy esquemática y brevemente. Nace éste en Queronea, Grecia, probablemente durante el reinado del emperador Claudio: si atendemos a la alusión que él mismo hace al viaje de Nerón a Grecia en E ap. Delph. (De E apud Delphos), año 67, se puede fijar la fecha de su nacimiento en el 47 d. C. C. P. Jones (JHS 56, 1966, pp. 61-74) cree que su muerte se produce antes del advenimiento del emperador Adriano al poder, o sea, el 117 d. C.; tal creencia tiene como fundamento el hecho de que la dedicatoria de la estatua de Adriano levantada por los anfictiones ${ }^{1}$ en 117 tiene el nombre

\footnotetext{
${ }^{1}$ La Anfictionía (del griego $\alpha \mu \varphi ı \kappa \tau \imath o v i ́ \alpha$, a su vez derivado de $\alpha \mu \varphi \hat{~}$ (ambos) $+\kappa \tau i ́ \zeta \omega ~(c o n s t r u i r)$, por lo que etimológicamente significa fundación conjunta) se trataba de una liga religiosa que agrupaba 12 pueblos (no ciudades), casi todos de la Grecia central. Tenía sus reuniones en el santuario de Deméter en Antela, cerca de las Termópilas. Como el oráculo de Delfos tenía ya un renombre mayor que el de Deméter, trasladaron allí la sede de esta confederación, sin por ello abandonar el otro santuario. Se reunían dos veces al año, alternando Delfos con Antela. Cuando se fundó tenía un carácter puramente religioso, pero poco a poco fue cambiando para terminar siendo verdaderamente política,
} 
del sacerdote Plutarco, en tanto que la del 125 d. C. tiene el de Aristótimo; pero, precisamente esto implicaría que podría haber muerto en el periodo que transcurre entre el 117 y el 125; por otra parte, la lectura del Pyth. Or. (De Pytiae oraculis, Sobre los oráculos de la Pitia) nos hace suponer que debió morir hacia el $126 \mathrm{~d}$. C. y que, antes de morir, a sus 80 años, debió conocer las reformas emprendidas por el emperador en Delfos. Queronea, hoy desaparecida, era una ciudad de Beocia. La mayor parte de su vida transcurrió en esta su ciudad natal. Hacia el año 67 d. C. estudia filosofía, retórica y matemáticas en la Academia de Atenas. Realizó muchos viajes; estuvo en Egipto y en Roma. Tuvo amigos influyentes, como Sosio Senecio y Fundano; al primero dedicó las Vidas Paralelas. Fue sacerdote de Apolo en Delfos, donde era el encargado de interpretar los oráculos de la pitonisa. Plutarco de Queronea es uno de los escritores más prolíficos, vivos y atractivos de la literatura griega. Su obra es representativa de una síntesis profunda del mundo greco-romano de aquel tiempo. Fue un erudito, filósofo, de amplios y profundos conocimientos históricos, y moralista, que vive momentos de esplendor del imperio romano, aunque también difíciles. Su ciudad natal, Queronea, situada en la Beocia del poeta Hesíodo, polariza toda su actividad literaria, en continuos viajes por el mundo romano de aquel entonces. Por tanto, se puede establecer un triángulo vital en su vida, determinado por tres lugares concretos, Roma, Queronea y Delfos, con un centro convergente: Atenas. Plutarco no es un filósofo al estilo de Platón o de Aristóteles, si bien, creó su propia escuela. Fue un gran conocedor de la historia y es considerado casi un historiador, aunque no lo fue en realidad. Es sugestivo al respecto un artículo que José Alsina Clota, catedrático que fue de la Universidad de Barcelona, escribió hace algunos años, precisamente con el título "El historiador Plutarco" (ANTHROPOS 20, Barcelona, 1999, pp. 90-101). Este mismo autor escribió un "Ensayo de una bibliografía de Plutarco (Eclás, 35, 1962, pp. 515-533), que sigue siendo válida a pesar de los años transcurridos y, también, en cierto modo más completa que la actualización que este mismo autor publicó posteriormente en ANTHROPOS ("Bibliografía de Plutarco", ANTHROPOS 20, Barcelona, 1999, pp. 128-131). Hoy los simposios nacionales e internacionales de la I.P.S. (International Plutarch Society) a la que pertenece la S.E.P. (Sociedad Española de Plutarquistas), van cumpliendo paulatinamente su objetivo de

con grandes influencias en decisiones de esta índole. Tenía un Consejo compuesto por los hieromnémones, hombres designados por cada comunidad. Los 12 pueblos designaban a los 24 miembros de este consejo: delfios, tesalios, focios, dorios (uno de Esparta y otro de Dórida), jonios, beocios, locrios, aqueos de Ftiótida, magnesios, enianos, malienos. 
continuar en la actualización y profundización de la investigación referente a su ingente obra.

\subsection{Moralia y Vidas Paralelas}

Tradicionalmente dividimos su obra en dos apartados: a) Moralia; b) Vidas Paralelas. La fama de Plutarco durante su vida hizo que poco después de su muerte se editaran incluso los escritos que dejó sin terminar; es más, algunos de ellos se falsificaron. Los Padres de la Iglesia, San Jerónimo y San Agustín, se interesaron ya en su tiempo por Plutarco. En realidad, Oriente conoció mejor que Occidente la obra de Plutarco; Occidente apenas conocía al verdadero Plutarco, que es suplantado por el falso Plutarco de la Institutio Traiani ${ }^{2}$. Dante, que es contemporáneo de Planudes, no sabe nada de él. En cambio, los sabios bizantinos del siglo XI tenían conocimiento del elenco plutarqueo: éste es, con pocas variaciones, el que nos ha llegado a nosotros y que hoy conocemos. No debe olvidarse el Catálogo de Lamprias $^{3}$ del siglo III o IV d. C., supuestamente atribuido a un hijo de Plutarco de este nombre. Con el cisma de Oriente en el 1054 ${ }^{4}$, con la consiguiente separa-

2 Juan de Salisbury en el libro V del Polycraticus habla de Plutarco como maestro del emperador Trajano, pero es de época posterior (entre siglo IV y V d. C.)

${ }^{3}$ El Catálogo de Lamprias contiene un elenco de la obra de Plutarco; fue redactado en el siglo III o en el siglo IV d. C. y atribuido a Lamprias, que según la tradición (Léxico de Suda) fue uno de los hijos de Plutarco; si bien, parece ser que Plutarco no tuvo ningún hijo con este nombre, y el catálogo adolece de múltiples imperfecciones. En él se citan 227 títulos, de los cuales nos han llegado sólo 83 , con ausencia de otros que no figuran en él y que se han conservado.

${ }^{4}$ En 857 el emperador griego Miguel, llamado el beodo, y su ministro Bardas, expulsaron de su sede de Constantinopla a San Ignacio, que reprendía sus costumbre crapulentas. Le reemplazaron por Focio, quien en seis días recibió todas las órdenes de la Iglesia. Focio se sublevó contra el Papa y se declaró patriarca universal. Fue descripto como "el hombre más artero y sagaz de su época: hablaba como un santo y obraba como un demonio". Su tentativa fracasó. Fue encerrado en un monasterio, donde murió en 886. En el año 1054, el Papa León IX quien, amenazado por los normandos, buscaba una alianza con Bizancio, mandó una embajada a Constantinopla encabezada por su colaborador, el cardenal Humberto de Silva Candida, y formada por los arzobispos Federico de Lorena y Pedro de Amalfi. Los legados papales negaron, a su llegada a Constantinopla, el título de ecuménico al Patriarca Miguel I Cerulario y, además, pusieron en duda la legitimidad de su elevación al patriarcado. El patriarca se negó entonces a recibir a los legados. El cardenal respondió publicando su Dialogo entre un romano y un constantinopolitano, en el que se burlaba de las costumbres griegas y, tras excomulgar a Cerulario mediante una bula que depositó el 16 de julio de 1054 sobre el altar de la Iglesia de Santa Sofía, abandonó la ciudad. A su vez, pocos días después (24 de julio), Cerulario 
ción de la iglesia griega de la romana, la obra de Plutarco, escrita originalmente en griego, fue casi olvidada en el Occidente cristiano. Sus escritos, sin embargo, comenzaron a ser conocidos en el siglo XIV en Occidente gracias al contacto de intelectuales latinos y orientales. La llegada a Occidente, tras la caída de Bizancio, de sabios griegos orientales contribuyó a despertar a Occidente de ese olvido del Queronense. El título de Moralia, que normalmente se traduce como Obras Morales y de Costumbres, es debido al monje bizantino Máximo Planudes, que en el siglo XIII hizo una recopilación de trabajos del autor de muy diverso orden. La primera traducción que se hace a una lengua romance de las Vidas Paralelas es debida a Juan Fernández de Heredia (1310-1396), Maestre de la Orden de San Juan de Jerusalén, época de Pedro IV el Ceremonioso, que en 1389 mandó traducir al aragonés la mayor parte de ellas, siguiendo la versión al griego bizantino de Demetrio (=Domitri) Talodiqui ${ }^{5}$. Alfonso Fernández de Palencia ${ }^{6}$, cronista y

respondió excomulgando al cardenal y a su séquito, y quemó públicamente la bula romana, con lo que se inició el Cisma. Alegaba que, en el momento de la excomunión, León IX había muerto y por lo tanto el acto excomunicatorio del cardenal de Silva no habría tenido validez; añade también que se excomulgaron individuos, no Iglesias. Con esto se ve que el Gran Cisma fue más bien resultado de un largo período de relaciones difíciles entre las dos partes más importantes de la Iglesia universal. Las causas primarias del cisma fueron sin duda las tensiones producidas por las pretensiones de suprema autoridad del Papa de Roma y las exigencias de autoridad del Patriarca de Constantinopla. Efectivamente, el Obispo de Roma reclamaba autoridad sobre toda la cristiandad, incluyendo a los cuatro Patriarcas más importantes de Oriente; los Patriarcas, por su lado, alegaban, según su entendimiento e interpretación de la Sagrada Tradición Apostólica y las Sagradas Escrituras, que el Obispo de Roma solo podía pretender ser un "primero entre sus iguales" o "Primus inter pares". Por su parte, los Papas, según su interpretación de la Tradición Apostólica y las Sagradas Escrituras, declaraban que "es necesario que cualquier Iglesia esté en armonía con la Iglesia (de Roma), por considerarla depositaria primigenia de la Tradición apostólica" (San Irineo de Lyon, s. II d. C.). También tuvo gran influencia el Gran Cisma en las variaciones de las prácticas litúrgicas (calendarios y santorales distintos) y disputas sobre las jurisdicciones episcopales y patriarcales. La Iglesia se dividía entonces en líneas doctrinales, teológicas, políticas y lingüísticas distintas (griego para las liturgias en Oriente, latín en las liturgias occidentales).

${ }^{5}$ Recogemos aquí la sugestiva nota de Adelino Álvarez Rodríguez (p. CX-CXI) sobre la personalidad del tal Talodiqui; según algunos, como Santhas (ibid.), Talodiqui no es nombre griego y debe rectificarse en Calodiqui ("buen juez") o Calotiki ("afortunado"). En 1960 Lutrell solucionó el problema: en el códice 321, f. 210v de la Royal Malta Library aparece el nombre de Calodiqui y se dice que era filósofo, escribano y natural de Tesalónica.

${ }^{6}$ Al parecer, natural, según unos, de Sevilla, pero, lo más probable, de Osuna; nació en 1423. Se educó en Burgos en el palacio del obispo Alonso de Cartagena, después estuvo en Italia al servicio del cardenal Besarión. Estudió humanidades con Jorge Trapezuntio. Entre sus diversas obras destacan las Vidas, que se editan en Sevilla en 1491; éstas se reeditan en Madrid en 1792, en la imprenta 
secretario de Enrique IV, traduce por primera vez las Vidas al castellano (1491), traducción defectuosa por su ignorancia del griego. También lo hace el humanista protestante español Francisco de Enzinas ${ }^{7}$, cuya traducción directa del griego es elogiada por Ménénez Pelayo: tradujo parte de ellas y las dedicó a Carlos V (1551). Diego Gracián ${ }^{8}$ tradujo las dos que faltaban a Enzinas y además los $M o$ ralia, cuya versión impresa apareció en 1548. Quevedo9 hizo una traducción glosada de la Vida de Marco Bruto. En el siglo XVII decae el interés por Plutarco, pero renace en el siglo siguiente. Ranz Romanillo ${ }^{10}$ (1759-1830) publica en 1821 los dos primeros tomos de su traducción de las Vidas, los dos siguientes salen en 1822 y en 1830 sale a la luz el quinto, que, además, es el año de su muerte; aun cuando hoy nos resulta un tanto arcaizante su lenguaje, es la traducción que en el siglo XX ha sido sumamente consultada por los especialistas, hasta que editoriales

Real, pero con la particularidad de que sólo se editaron dos tomos y se suprime el prólogo escrito por Alfonso Fernández de Palencia en la primera edición, en el cual se daba cuenta de los nombres de los traductores italianos de las Vidas al latín. Palencia, a pesar de haber estudiado con Besarión y Trapezuntio, no llegó a aprender el griego. La primera edición, la de Sevilla, contiene treinta vidas. Palencia lo que hizo es utilizar una traducción latina de las Vidas.; sabemos que en año 1471 aparece una traducción de Giovanni Antonio Campano; más tarde, en Venecia se edita una traducción latina debida a un grupo de humanistas que son citados por Palencia: su primera edición de 1491, de la que existe un ejemplar en la Biblioteca Nacional de Madrid. Como 1491 es fecha coincidente con la edición sevillana de Palencia, y como la edición veneciana no fue la primera, forzosamente Palencia debió traducir el texto latino de la edición veneciana de 1478.

${ }^{7}$ Nació Encinas en Burgos en 1520. Estudió en Alcalá, en París y en el Colegio Trilingüe de Lovaina. Se hace luterano y, en su afán por oír las enseñanzas de Melachton, se matricula en 1541 en la Universidad de Wittenberg. Sufrió los procesos inquisitoriales. A pesar de todo, dedica en 1551 al emperador Carlos V su traducción de las Vidas. Muere el 30 de diciembre de 1552 por causa de una epidemia de peste. Tuvo un buen conocimiento del griego que le mereció el juicio elogioso de Melachton.

${ }^{8}$ Nació en Alderete, cerca de Tordesillas, hijo de un armero mayor de los Reyes Católicos. Estudió en Paría y Lovaina. Su vida fue larga ya que alcanzó hasta los 90 años. Fue traductor de lenguas extranjeras para el emperador Carlos V. Traductor de las Historias de Tucídides (Salamanca, 1564) y buena parte de Jenofonte (Salamanca, 1552), entre otras. En el prólogo de la primera edición de las Morales (1548) critica la traducción de Palencia: según él, deberían llamarse Muertes más que Vidas por su oscuridad e infidelidad.

${ }^{9}$ No completa: hasta algo menos de la mitad; algunos pasajes están abreviados. Sus contemporáneos elogiaron sus conocimientos del griego y Lope en el Laurel de Apolo le llama el "Lipsio de España". Pero, a pesar de todo, no la manejaba con soltura. Utilizó una versión latina para la Vida de Marco Bruto: eso es lo que vienen a demostrar la forma latina de los nombres, no pocos giros sintácticos $\mathrm{y}$ algunos errores.

${ }^{10}$ Intervino en política; tomó parte en las Cortes de Bayona de 1808 y fue consejero de Estado; esto le granjeó el título de afrancesado. Tradujo los Discursos de Isócrates. 
como Gredos y otras crearon nuevas ediciones con traducción en lengua española. Jacques Amyot en 1559, catedrático de Bourges y más tarde obispo de Auxerre, hizo una traducción al francés de las Vidas, que despierta una gran popularidad del autor en Francia; éstas en el siglo XVIII hace latir el corazón de Víctor Alfieri; influye en Montaigne (influyó en su Essais) y Rabelais. Plutarco apasiona a Montesquieu, a Rousseau, a Napoleón, a Bacon, a Shakespeare: éste último se inspiró en algunos personajes de las Vidas. Erasmo, Melachton, Zuinglio, Federico el Grande, Goethe, Schiller, Beethoven también fueron entusiastas lectores de este autor, lo mismo que Quevedo y el humanista Cristóbal de Villalón. Concretamente, Rousseau de niño se aprendió de memoria las Vidas y los Moralia, y sacó de ellos notas y extractos ${ }^{11}$. Durante la Revolución francesa la popularidad de Plutarco alcanzó cotas elevadas, e incluso se escribían tragedias inspiradas en sus héroes. Carles Riba (1893-1959) ${ }^{12}$ hizo una excelente traducción al catalán, en cuya primera edición (1926), dedicada a Francesc Cambó, se dice literalmente, en lengua catalana, lo siguiente, que traduzco al castellano: "Esta primera versión catalana de las Vidas Paralelas está dedicada a Francesc Cambó con la esperanza de que serán para él realidad un día las otras aspiraciones que presidiendo el trabajo del atrevido traductor han hecho de ella en tiempo de daño y vergüenza más aún que una joya un deber".

\section{Juan Fernández de Heredia}

2.1. Pero hablemos de Juan Fernández de Heredia, primer traductor, o, más bien, promotor, de las Vidas Paralelas a una lengua romance, concretamente, al aragonés. Nació éste en el seno de una familia de ricohombres de Aragón hacia el

\footnotetext{
${ }^{11}$ Parece ser que Rousseau a los seis años leyó las Vidas de Amyot y a los ocho las sabía de memoria.

${ }^{12}$ Poeta catalán y profesor de lenguas clásicas, excelente traductor de los clásicos. A los diecisiete años publicó en hexámetros las Bucólicas (1911) de Virgilio; poco después, la Odisea (1919), también en hexámetros. En 1920 publica la Antígona y la Electra de Sófocles en verso. En 1922 entra a formar parte de los colaboradores de la "Fundació Bernat Metge", creada por Cambó, e inicia su actividad de filólogo, editor y traductor hasta el final de su vida. Así, tradujo los Memorables (1923), alguna obra socrática de Jenofonte (1924), y a partir de 1926 emprende la traducción de las Vidas; después de la guerra civil reedición y rectificación de su Odisea y Antígona y en 1940 publica el volumen octavo de las Vidas. El último de los quince volúmenes se publica en 1946; con lo cual dedicó veinte años a la función traductora de esta obra, que sigue la edición de Lingdskog-Ziegler. Es una buena traducción.
} 
1310, en Munébrega, cerca de Calatayud, provincia actual de Zaragoza. Su padre, García Fernández de Heredia, caballero importante durante el reinado de Jaime II, estaba encargado en 1301 de la defensa de Ródenas, en 1316 formaba parte del séquito de la infanta Leonor, y dejó tres hijos: Blasco, Juan y Gonzalo. Juan Fernández de Heredia, a instancias de su hermano primogénito don Blasco, que no tenía descendencia, para asegurar su descendencia masculina, le indujo a casarse por segunda vez. De su primer matrimonio, tuvo dos hijas, Toda y Donosa. Del nuevo matrimonio nacieron Juan y Teresa. Pero, según José Vives (Juan Fernández de Heredia, Gran Maestre de Rodas. Vida, Obras, Formas Dialectales, 1927) los dos matrimonios de Juan Fernández de Heredia no pasan de ser una leyenda piadosa, ya que sus cuatro hijos mencionados arriba aparecen en un documento de legitimación como hermanos ilegítimos nacidos «ex religioso Patre et solutis tamen mulieribus». Pero al final don Blasco logró tener la descendencia deseada y Don Juan, viudo ya de su segunda esposa, como no tenía hacienda para dar a sus hijas, determinó tomar el hábito religioso, e ingresó en la Orden de San Juan de Jerusalén ${ }^{13}$, religiosa orden militar donde llegó a escalar puestos de categoría. Desde luego, los documentos conocidos lo presentan muy pronto relacionado con

\footnotetext{
${ }^{13}$ Sobre esta Orden, he aquí algunos datos. En 1112, el papa Pascual II asimila el Hospital de S. Juan de Jerusalén a una orden religiosa y le exime del pago del diezmo sobre sus tierras. En 1115, esta exención es combinada con el derecho de adquirir y recibir diezmos sobre las tierras de otro. Por esta fecha, los hermanos de S. Juan habían abandonado ya su primitiva regla para seguir la de los canónigos de S. Agustín, más adaptable a su función hospitalaria. Los miembros de esta Orden, de reclutamiento sobre todo nobiliario, se llamaban "humildes servidores de los pobres" y practicaban una caridad a la escala de sus inmensos dominios. Así, hacia finales del s. XII, pueden poner un millar de camas a disposición de los enfermos en la ciudad de Jerusalén, lo que es comparable a los grandes hospitales modernos. En 1245, S. Juan de Acre era el último refugio que quedaba de los Hospitalarios en Tierra Santa. Cuando en 1249, el rey S. Luis de Francia desembarca en Damieta, los Caballeros lo apoyan en sus empresas. Pero en 1291 Acre -aunque bien defendida por los caballeroscede ante el asedio de los musulmanes. Después de la toma de S. Juan de Acre por el sultán mameluco del Cairo Al Malik Al-Ashraf Kalil, el 18 de mayo de 1291, los supervivientes de las Órdenes Militares se refugian en Chipre e intentan hacer frente a una nueva situación, y, habiendo perdido totalmente Tierra Santa, están condenados a volver sus armas hacia otros campos de batalla. Los hospitalarios de S. Juan, después de 1291 y tras una corta estancia en Chipre (1291-1307), donde las relaciones con el rey Enrique II de Lusignan son cada vez más tensas, deciden conquistar Rodas e instalarse allí antes de volver a tomar el camino de Tierra Santa. Esta decisión hace de Rodas y del Dodecaneso un estado original hacia el cual convergen, durante más de dos siglos, las fuerzas vivas de toda Europa. La conquista de Rodas tuvo lugar en 1307. Desde entonces se suceden los Grandes Maestros de la Orden en esta ciudad, hasta el número de 18, entre ellos, tres españoles. Juan Fernández de Heredia fue el primero de todos ellos.
} 
los caballeros hospitalarios de la Orden de San Juan de Jerusalén, ocupada en la defensa del Asia Menor y la recuperación de los Santos Lugares. En 1328 era ya miembro de la Orden, y ocupó cargos como el de lugarteniente del comendador de Alfambra (1333), luego comendador de Alfambra, Villel y Zaragoza (1334). $\mathrm{Su}$ ascendencia en la Orden del Hospital fue rápida y segura y su influencia en la corte aragonesa, poderosa. Llegó a ser Castellán de Amposta, la dignidad más alta de la Orden en la Corona de Aragón, pero renunció a esta castellanía para no enemistarse con Jaime II, cuyo hermano Don Sancho, hijo bastardo de Pedro III y de Doña Inés de Zapata, la había también solicitado. En 1335 es prior de la Orden en Castilla. En 1338, Pedro IV lo nombró consejero suyo, e intervino en las contiendas de este monarca con la nobleza aragonesa y valenciana. Pero las complicaciones no tardaron en surgir. Juan Fernández de Heredia aspiraba a la castellanía de Amposta, ocupada desde 1325 por don Sancho de Aragón, tío del monarca. En 1341, Pedro apoyó las intrigas de Juan Fernández de Heredia para ocupar dicho puesto. Don Sancho se resistió y encarceló a Juan Fernández de Heredia. El rey ordenó su libertad y los visitadores de la Orden nombraron a Juan Fernández de Heredia castellán en junio, el cual fue a prestar homenaje a Pedro IV. Pero éste, dudando de la legalidad de la elección, no lo aceptó y pidió a los hospitalarios aragoneses que reconocieran a don Sancho. Más aún, en septiembre del mismo año escribió al gran maestre de Rodas quejándose de la conducta irregular de Juan Fernández de Heredia, y en noviembre ordenó a Juan Fernández de Marciella que desde Teruel se apoderase de Alfambra. Juan Fernández de Heredia se defendió y el rey lo mandó arrestar en 1342. Esta situación duró poco. Don Sancho, viejo y enfermo, murió en enero de 1346 y Pedro IV, prefiriendo tener a Juan Fernández de Heredia de su parte, escribió al maestre de Rodas solicitando para su protegido la castellanía de Amposta, la cual fue ocupada por aquél en diciembre de 1346, después de unos meses de lugartenencia. De este modo Juan Fernández de Heredia acababa de conseguir uno de los puestos más importantes del reino. Ocupó el cargo de castellán de Amposta desde 1346 hasta 1377. Durante este tiempo su actividad fue intensa y variada. Dentro del Hospital continuó su marcha ascendente, que culminará con el cargo de Gran Maestre; en calidad de tal de 1354 a 1355 realizó un viaje a Rodas para fortalecer la disciplina; en 1355 fue nombrado prior de Castilla y León; en 1356, de Saint-Gilles, Provenza; en 1369, de Cataluña. En la corte aragonesa su intervención era decisiva, brillante e imprescindible; diplomáticamente desempeñó delicadas misiones en Castilla, Navarra, Inglaterra y Francia. En la guerra de los Cien Años fue hecho prisionero por los ingleses en Crecy (1346). Fue el embajador obligado de Pedro IV y Juan I en la corte papal de Avignon. Comprendiendo que no le iba a ser fácil medrar en 
la corte aragonesa, se decidió pasar a la pontificia de Avignon ${ }^{14}$, probablemente hacia el 1344, en tiempo de Clemente VI. Allí llegó a ser el hombre de confianza de seis papas. Inocencio VI lo nombró gobernador de esta ciudad (1356); Urbano V y Gregorio XI lo hicieron su consejero especial. La posición de Fernández de Heredia llegó a ser tan preponderante que en 1371 se excusó ante Pedro IV para servir al papa y en 1376 no sólo fue el encargado de dirigir la flota que condujo a Gregorio XI de Marsella a Roma, sino el portaestandarte papal en su retorno a la Ciudad Eterna. En Roma organizó el pasaje a Oriente. Durante los preparativos, murió en Rodas Roberto de Jully, y Juan Fernández de Heredia fue investido por el papa Gregorio XI como gran maestre el 24-IX-1377.

2.2. Pues bien, en la ciudad francesa de Avignon tuvo lugar uno de los movimientos renacentistas más importantes del redescubrimiento de la literatura grecolatina para Occidente. El establecimiento de la corte papal en Avignon en 1309 hizo que esta ciudad tuviera un papel primordial en la génesis del Humanismo italiano y europeo. A Avignon venían clérigos y monjes del lejano Oriente cristiano; de manera que la gran cantidad de códices griegos que poseía la biblioteca papal podían ser leídos por personas de aquella ciudad en la que se enseñaba y se aprendía la lengua griega ${ }^{15}$. Por tanto, Avignon fue decisiva en el descubrimiento de Occidente de la obra de Plutarco, que habíamos afirmado arriba que en Occidente era casi desconocido. Baste decir que en Avignon fue promovida la primera traducción latina de un opúsculo de los Moralia de Plutarco, De cohibenda ira y que en la Biblioteca del Cabildo de Sevilla ${ }^{16}$ se conservan 17 folios de pergaminos con la traducción latina de De furoris abstinentia realizada por Simón Atumano, si bien es verdad que no es del propio Simón, sino una copia hecha o mandada hacer por Coluccio Salutati ${ }^{17}$. El texto va precedido de una carta fechada en Aviñon (20

\footnotetext{
${ }^{14}$ Cf. Lasso de la Vega (EClás. 35, 6, 1962, pp. 451-514).

${ }^{15}$ Según Lasso de la Vega, con fines misioneros (op. cit., p. 453 y n. 4), si bien no explica el significado de tal afirmación; sólo hace a pie de nota un apunte bibliográfico citando obras de a B. Altaner (1933 y 1936), donde se trata de este tema. En todo caso, lo importante es que se produjo una corriente de atracción cultural y humanística hacia Avignon importante.

${ }^{16}$ Cf. J. S. Lasso de la Vega, art. cit.

${ }^{17}$ Coluccio Salutati, nacido junto a Lucca y educado en Bolonia, se formó en la escuela de retórica del amigo de Francesco Petrarca, Pietro da Muglio, y se convirtió en canciller de Florencia en 1375, poco después del fallecimiento de Petrarca y Giovanni Boccaccio. Aunque había tenido frecuentes contactos con ambos, su amistad con el primero nunca pasó del epistolar. Fue un activísimo epistológrafo y se conservan todavía centenares de cartas particulares suyas. Incluso como canciller de
} 
de enero 1373) dirigida al cardenal Pietro Corsini; éste aprovechó la estancia en Avignon de Simón Atumano, antiguo monje de Constantinopla ${ }^{18}$ que se pasó a la Iglesia de Roma, para solicitarle que tradujera el De cohibenda ira porque el original griego se encontraba a su disposición. Parece ser que Coluccio Salutati no estuvo en Avignon, pero tenía buenos contactos con personalidades importantes de la Corte papal. Hacia el 1392 el cardenal Pietro Corsino le enviaba desde Avignon un ejemplar de la traducción latina del De cohibenda ira de Plutarco realizada por Simón Amuntano; la impresión de Salutati sobre la traducción fue desfavorable: no le gustó y la califico como "semigreca". Resulta que Salutati no sabía griego, pero hizo una paráfrasis del mismo en un buen latín que remitió al cardenal precedida de una carta dedicatoria. Poco después recibe casualmente la noticia de que las Vidas han sido traducidas por encargo de Juan Fernández de Heredia y escribe una larga epístola (1 de feb. de 1393 o 1394) a éste rogándole el envío del ejemplar, a cambio de ofrecerle un ejemplar de la Odisea latina de Leoncio Pilatos.:

Ceterum scio quod de graeco in graecum vulgare et de hoc in aragonicum Plutharcum de historia quadraginta octo ducum et virorum illustrium interpretari feceris. Habeo quidem rubricarum maximam partem. Cupio, si fieri potest, hunc librum videre. Forte quidem transferam in latinum.

Al parecer su propósito era hacer una traducción de ellas al latín. La demanda de Salutati no tuvo éxito, hasta que Benedicto XIII, para ganarlo a su causa, le escribe anunciándole el envío de la traducción solicitada, la cual debió llegar a sus

Florencia fue el escritor oficial de las mismas para la república y se conservan también varios centenares. No en vano fue un entusiasta divulgador de las Epistulae ad familiares de Cicerón, cuyos dieciséis libros se hizo copiar en 1392. Valoró más el espíritu cívico de Cicerón que el desengañado Petrarca. Con ayuda de sus amigos logró reunir una biblioteca particular de 800 volúmenes escogidos muy importante. Era un lector voraz, amante sobre todo de la poesía, a la que colocaba por encima de las demás artes, pero también reflexivo y atento a cuestiones de crítica textual, religión y filosofía. Aunque no fue un humanista muy fecundo, fue un importante maestro, accesible para las generaciones jóvenes. Su obra en prosa más importante fue una interpretación alegórica de los doce trabajos de Hércules, que quedó incompleta. Puede ser considerado el primer escritor del Renacimiento sobre teoría poética y crítica literaria. Pese a que no conocía el griego, se preocupó por traer a un buen maestro de ese idioma a Florencia para que enseñase a los eruditos locales: el erudito bizantino Manuel Crisoloras. Los alumnos de Salutati, entre ellos Leonardo Bruni, se convirtieron en entusiastas discípulos de Crisoloras.

${ }^{18}$ Para esta cuestión, cf. Lasso de la Vega, art. cit. 
manos. No se realizó la traducción al latín, pero sí, en 1395 o 1396, la traducción al italiano de la versión aragonesa ${ }^{19}$.

Pues bien, volvamos atrás: a Avignon se fue nuestro hombre. Pero el papa que le otorgó más sus favores fue Inocencio VI. Desde 1356 el apoyo de Inocencio VI, que le tenía en gran estima, le vale ser nombrado por éste prior de Saint-Gilles, en contra del parecer del mismo Gran Maestre de la Orden: fue nombrado Prior de Saint Gilles y Gran Prior de Castilla. Se afinca en la corte papal de Avignon, donde el Papa le nombra gobernador de la ciudad y le encarga su defensa. Mantuvo buenas relaciones con Urbano V y Gregorio XI, y también con el aragonés Benedicto XIII (el antipapa); según el historiador aragonés Jerónimo Zurita, cuando Pedro Martínez de Luna, Cardenal de Aragón y ya papa Benedicto XIII, llegó a ocupar el trono pontificio en el exilio papal de Avignon, encontró que estaban empeñados incluso los ornamentos sagrados de la capilla reservada al titular de la Sede de San Pedro y fue Juan Fernández de Heredia quien con sus bienes rescató a Don Pedro de tanta necesidad y con ello le permitió inaugurar con fuerza su largo y dramático mandato. Desde la sede papal Juan Fernández de Heredia fue embajador de los monarcas de Aragón Pedro IV y Juan I. Fue investido Gran Maestre de la Orden de San Juan del Hospital el 24 de diciembre de 1377 y lo fue hasta su muerte en 1396. Desde tales cargos colaboró tanto con los papas como con los reyes de Aragón y Castilla, a cuya disposición puso la fuerza militar más compacta de la Cruzada de aquel momento. En 1377 preparó una expedición a Morea, a donde se dirigió desde Nápoles para anexionar Acaya a las posesiones del Hospital y conquistó Naupacto ${ }^{20}$ (=Lepanto) a los albaneses, si bien el buen resultado de la expedición se estropeó cuando fue capturado en el golfo de Arta por el príncipe albanés Ghin Bua Spata, aliado de los turcos; fue vendido como cautivo a los turcos y la Orden tuvo que pagar un cuantioso rescate. Durante su cautiverio, de algo menos de un año (1378-79), se produjo el Gran Cisma de Occidente; su cautiverio duró

\footnotetext{
${ }^{19}$ El 17 de noviembre de 1384 el infante don Juan, amigo de Heredia, le dice que conoce en Avignon a un "philosopho de Grecia que le traduce libros del griego al aragonés". Vuelve a escribirle el 11 de diciembre del mismo año diciéndole que cuando llegue el "philósopho griego", le envíe copia de todos los libros que traiga de Grecia. Rubió i Lluch cree que el tal "philosopho griego" es el obispo Nicolás (Nicolaus). Para más detalles cf. Adelino Álvarez Rodríguez, Plutarco. Vides Semblantes, Zaragoza, 2009, p. CXXVI.

${ }^{20}$ Naupacto (lat. Naupacte, gr. Naupaktos, conocida también como Lepanto (it. Lepanto) es una ciudad de la prefectura de Etolia-Acarnania, en la costa norte del estrecho que separa el golfo de Patras del golfo de Corinto.
} 
poco: el 30 de mayo de 1379 fue liberado y marchó a Rodas, sede principal de la Orden. En 1378, unos cardenales eligieron a Urbano VI; otros a Clemente VII. Juan Fernández de Heredia y la mayoría de los hospitalarios siguieron a Clemente VII. El cisma no sólo dividió a los hospitalarios, sino que les hizo abandonar por el momento todo intento de afincarse en Morea. Juan Fernández de Heredia, recobrada la libertad, estuvo tres años en Rodas ocupado en la defensa y organización de la orden hasta el 9 de abril de 1382; supo resistir al imperio otomano durante las dos décadas de su mandato y defendió la sede de los hospitalarios de Rodas, ocupó Corinto y defendió con éxito Morea. Regresó a Avignon, y, cuando se declaró el cisma de este nombre, se inclinó por Clemente VII, y, luego, por su paisano Bendicto XIII. Falleció en 1396. Sus restos fueron trasladados a Caspe (1522) donde fue enterrado en el sepulcro que él mismo mandó labrar en la iglesia parroquial de Caspe, según Lasso de la Vega ${ }^{21}$, "asaz deteriorado y sin leyenda alguna que recuerde su nombre", afirmación sorprendente, dado que la colegiata, junto con su sepulcro, fueron víctima de los furores y barbaries de la guerra civil española, no habiendo quedado nada de sus restos.

\subsection{Sus obras}

He aquí sinópticamente un resumen de sus obras:

1. Grant Crónica de Espanya, en tres partes (se conservan dos), que es una compilación (Grant Crónica de Espanya I, desde sus inicios hasta el 711; Grant Crónica de Espanya III, traducción de la General Historia de Alfonso X.

2. Crónica de los Conquiridores, en dos partes (I y II), serie de biografías de 16 personajes famosos en la primera parte y 18 personajes famosos en la segunda; comprende desde Marco Antonio hasta Jaime I el Conquistador.

3. Crónica o Libro de los Emperadores que fueron en Grecia, traducción parcial (sólo los últimos cuatro libros) de la obra griega Epitome Historiarum de Juan Zonaras (s. XII).

4. Crónica de Morea o Libro de los fechos et conquista del principado de Morea, parte traducción y parte elaboración original.

\footnotetext{
${ }^{21}$ Art. cit.
} 
5. Flor de las Ystorias de Orient, traducción hecha según las versiones catalana y francesa de la obra Flor de les estoires de la terre d'Orient, del príncipe armenio Aitón de Gorigós.

6. Libro de Marco Polo, que recoge los viajes de este aventurero veneciano; traducción de una versión catalana de Il Milione.

7. Libro de las actoridades o Rams de Flores, florilegio tomado de la colección de la Summa Collationum (Communiloquium) de Juan de Gales, en versión catalana, y del Valerio Máximo.

8. Secreto de los Secretos, traducción de una obra en versión latina atribuida a Felipe de Trípoli; es una guía de príncipes.

9. Ystoria Troyana, basada en la obra en latín de Guido delle Colonne, Historia destructionis Troiae, sobre la guerra de Troya.

10.Vidas semblantes o traducción de 39 Vidas de las Vidas Paralelas de Plutarco.

11. Traducción de todos los discursos de la Historia de la Guerra del Peloponeso de Tucídides.

12.Ystorias de Orosio, o Historia contra los paganos, traducción de una versión italiana de la Historia adversus paganos de este autor.

13. Traducción de Eutropio, hecha a base de la Historia Romana de Paulo Diácono, que es, a su vez, epítome de Breviarium ab urbe condita de Eutropio..

14. Cartulario Magno, que contiene unos tres mil documentos sobre la castellanía de Amposta.

15.Cronicon mundi. Comprende la Cronica de San Isidoro de Sevilla.

Son obras atribuidas a la promoción cultural de nuestro personaje; algunas se han perdido. Como puede comprobarse, no son pocas las que fueron de su interés que trataran de tema griego o latino. A nosotros, sin embargo, en este momento, nos interesa las que aparecen en el apartado 10, las Vidas semblantes.

Se puede decir que en lo que respecta a su labor literaria, histórica y humanística Juan Fernández de Heredia vino a representar en la Corona de Aragón el parangón de lo que fue en Castilla Alfonso X el Sabio. Entre las intrigas de corte y curia, guerras y cautiverios, este gran hombre de estado encontró tiempo para formar una rica biblioteca y existen testimonios de distintos personajes de su tiempo que elogian su cultura y saber, y entre ellos varias cartas del rey Pedro IV y de su hijo don Juan en la que se le piden o devuelven libros que les había pres- 
tado $^{22}$. Su biblioteca debió de ser considerable: en 1377 Gregorio XI le permitió disponer en vida y muerte de «los libros que compilaste y mandaste escribir», y el erudito italiano Coluccio Salutati solía decir que la biblioteca de Heredia tenía todos los libros que uno podía desear. Parte de esos libros pasaron a la biblioteca regia y otros fueron a la propiedad del primer Marqués de Santillana, Íñigo López de Mendoza; luego, durante cuatro siglos estuvieron en la biblioteca de la Casa de Osuna, y a finales del siglo XIX pasaron a formar parte de los fondos de la Biblioteca Nacional de Madrid o de la Biblioteca Escurialense, como sucedió con el Tucídides.

Como resulta que tuvo una vida agitada, se supone que no escribió personalmente, ni tuvo tiempo y tranquilidad para ello, ninguna de las obras que figuran con su nombre, y que su labor fue simplemente de promoción y dirección. Así, por ejemplo, con la Grant Crónica de Espanya y la Grant Crónica de los Conquiridores: esta última comienza con el romano Marco Antonio y acaba con Jaime I, de las cuales hay manuscritos, en su mayoría inéditos, en la Biblioteca Nacional de Madrid. Gracias a la presencia de Juan Fernández de Heredia en Rodas fueron encargadas las primeras traducciones de Tucídides y Plutarco a una lengua romance; los tres años que estuvo en esta isla de Rodas parecer ser que hicieron que le viniera a la mente la idea de traducir algunas obras griegas y debió instruirse en la historiografía helénica. La traducción encargada por Heredia de la Historia de la Guerra del Peloponeso de Tucídides se conserva en el codice Matritensis 10801, copiado hacia el 1384 en Avignon, pero es, desgraciadamente, parcial, puesto que se limita sólo a los discursos. En Rodas debió conocer a Demetrio (Dimitri) Talodiqui, que tradujo al griego bizantino algunas de las obras que interesaban a Heredia, entre ellas Tucídides y Plutarco, y probablemente tuvo la oportunidad de entrar en contacto con el traductor de ellas al aragonés, Nicolás, obispo de Drenópolis (antigua Adrianópolis de Etolia), que, por haber residido gran parte de su vida en Grecia, conocía a la perfección el griego bizantino. Este obispo fue quien, por encargo de Heredia, tradujo luego en Avignon al aragonés el texto de Talodiqui de las Vidas Paralelas de Plutarco y los discursos de Tucídides que están incluidos en su Historia de la Guerra del Peloponeso. Es Rubió i Lluch quien en 1921, en la introducción a la segunda parte de sus Documents ${ }^{23}$ identifica el

\footnotetext{
${ }^{22}$ Cf. al respecto, J. S. Lasso de la Vega, art. cit.

${ }^{23}$ Documents per a l'Historia de la cultura Catalana Mitgeval o Documentos para la historia de la cultura catalana medieval (1907-21). Antonio Rubió i Lluc fue un historiador y erudito catalán,
} 
traductor al aragonés con "Nicolaus", obispo de Drenópolis (episcopus drenopolitanus). En $1927 \mathrm{~J}$. Vives descubre que varias $\operatorname{Vidas}^{24}$ o fragmentos fueron incorporadas a la Grant crónica de Espanya y a la Gran crónica de conquiridores.

Con respecto a la versión de las Vidas hasta fines del siglo XIX solamente se conocía el texto de una traducción italiana de fines del siglo XIV ${ }^{25}$ : El abate Mehus, un erudito del siglo XVIII, en su edición del epistolario de Ambrosio Traversario $^{26}$ describe prolijamente los códices que se conservan de ella en las Bibliotecas de Florencia, que son manuscritos descritos en el Catálogo de Bandini

que nació en Valladolid y murió en Barcelona (1856-1937). Fue hijo del poeta Joaquim Rubió i Ors. Estudió en Barcelona donde fue discípulo, entre otros, de Manuel Milà i Fontanals y fue compañero de estudios de Marcelino Menéndez y Pelayo. Se doctoró en 1878, y en 1880 fue nombrado auxiliar de la facultad de Letras de la Universidad de Barcelona. En 1885 fue nombrado catedrático de historia de la literatura en la universidad de Oviedo; luego se traslada a Barcelona para cubrir la vacante de Milà i Fontanals, donde en 1889 fue nombrado miembro numerario de la Acadèmia de Bones Lletres de Barcelona. El 1904 inició su docencia en literatura catalana en la cátedra de Literatura catalana fundada por los Estudis Universitaris Catalans. En 1906 fue vicepresidente del Primer Congreso Internacional de lengua Catalana. En 1907 ingresó en el Institut de Estudis Catalans, del que, poco después, fue nombrado presidente. Sus viajes a Italia y Grecia le pusieron en contacto con las fuentes documentales de esos territorios en lo que respecta a su relación con Cataluña y la dominación catalanoaragonesa con el ducado de Atenas. Cabe citar en este sentido, además de los Documents, La expedición y dominación de los catalanes en Oriente juzgada por los griegos (1983), Catalunya a Grècia (1906); La acrópolis de Atenas en la época catalana (1908); La lengua catalana a Grècia (1917). También, con respecto al tema que nos ocupa, Estudi sobre la elaboració de la Crònica de Pere el Ceremoniós (1910) y La cultura catalana en el regnat de Pere III (1914). Tuvo como discípulo a Ángel Balbuena Prats. Su amor por la cultura griega se refleja en que tradujo Anacreonte al catalán y al castellano, en que reunió una abundante documentación sobre la presencia medieval catalana en los ducados de Atenas y Neopatria y en que fue defensor de las aspiraciones territoriales griegas sobre Creta y en 1897, inspirado por Enric Prat de la Riba, escribió un manifiesto de adhesión a la causa griega. Todo ello le mereció ser nombrado cónsul honorario de Grecia en Barcelona. Cf. al respecto, M. Cerezo Magán, Ataraxia 1, 1966, Sobre la expedició de catalans a Grècia, pp. 16-17.

${ }^{24}$ Concretamente, 6 Vidas.

${ }^{25}$ Para esta cuestión cf. J. S. Lasso de la Vega, art. cit., p. 459-460.

${ }^{26}$ Ambrosio Traversario, nació en Portico di Romagna en 1386. Educado en la Florecia de su época, el centro del platonismo por aquel entonces, aprendió griego con Manuel Crisoloras y, siendo muy joven, profesó como monje en la orden de la Camáldula, comunidad monástica continuadora de los preceptos de la regla benedictina fundada por San. Romualdo en la primera parte del s. XI. Formó parte del círculo de Cosme de Medici, a quien recomendó la adquisición de más de 200 manuscritos griegos procedentes de Bizancio. 
(Catalogus codicum italicorum bibliothecae Mediceae Laurentianae, Florencia, 1778, coll. 242 y 4699). El abate jesuita valenciano Juan Andrés Morell visita por esta misma época Florencia y escribe a su hermano Carlos en sus Cartas familiares sus impresiones del viaje que realizó por Italia entre 1785 y $1791^{27}$. Sirviéndose de Mehus como guía, en la Biblioteca Ricardiana de Florencia (son tres las bibliotecas de Florencia: Santa Croce, Laurenziana y Ricardiana) contempla ciertos códices de las Vidas traducidas al italiano, que dan noticia de una traducción española en la cual se basan; ésta es la versión encargada por Juan Fernández de Heredia y solicitada por el humanista Coluccio Salutati. En la carta IV, de Juan Andrés Morell, después de decir y describir todo lo que ve en las bibliotecas de Florencia, se expresa en estos términos ${ }^{28}$ :

La Ricardiana, fundada en el siglo XVI por Ricardo Riccardi, discípulo del célebre Pedro Victorio, es conocida en toda Europa por las muchas noticias que ha suministrado al erudito Mehus y a otros escritores, por lo que ha servido a algunos editores antiguos, y por los varios códices de ella que ha publicado Lami, el qual ha sido por tantos años su Bibliotecario é ilustrador (...)

Luego cita los códices que ve en la biblioteca y continúa ${ }^{29}$ :

Acompañome el abate Mehus, sujeto doctísimo singularmente en las cosas de Florencia,y el mismo dueño (...). Los manuscritos de esta son unos 1800, parte orientales, parte griegos, parte latinos, parte provenzales y muchísimos italianos. Los orientales son unos 40 , pero no contienen cosas particularmente notables. Los griegos unos 20, dos de ellos apreciables por su antigüedad, uno de las obras morales de Plutarco, y otro de San Basilio (...). Dicen, pues, estos códices (de los que solo en la biblioteca del subdecano Ricardi hay tres diferentes) que la Cronica de Plutarco (así llaman al libro de los varones ilus-

\footnotetext{
${ }^{27}$ Cf. al respecto, Enrique Giménez López Bolonia, Florencia, Roma. Cartas familiares I Juan Andrés Morell, Publicaciones de la Universidad de Alicante, 2004, 559 págs.

${ }^{28}$ Respetamos la grafía y acentuación del original.

${ }^{29}$ Lo que está en cursiva corresponde al original que aparece así: en cursiva.
} 
tres) fue traducida de gramática griega (esto es de griego antiguo, o, como dicen, literal) en griego vulgar, por un filósofo griego llamado Domitritalodiqui ${ }^{30}$, y del griego en aragonés por un frayle predicador Obispo de Tudernopoli (aquí varian los códices, uno Tudernopoli, y otro Andrinopoli) muy suficiente griego, instruido en varias ciencias, grande historiador $y$ experto en varias lenguas ${ }^{31}$ por mandato del $M$. R. en Cristo padre y señor Messer fray Juan de Eredia y Señor de la Orden del Hospital de San Juan de Jerusalen (...). Ya ves como se pueden sacar aquí algunas noticias pertenecientes á los españoles, y mas por la variedad que hay en los mismos códices, en los que se ponen mas ó menos títulos al Gran Maestre Eredia, y mas ó menos elogios al frayle predicador, cuyo nombre no se expresa. El abate Mehus en su vida de Ambrosio Camandulense, que es un tesoro de erudición de historia literaria, habla largamente de estos códices, y de la intención que Coluccio Salutati tenía de sacar otra traduccion latina de la aragonesa (...). Y es de observar que esto era aun antes de ser Eredia Gran Maestre quando solo era Castellan de Amposta, que es decir antes del año $1376^{32}(\ldots)$.

Pero el texto aragonés de la versión encargada por Heredia era desconocido hasta que el erudito hispanista Alfred Moret-Fatio (s. XIX) identificó con él el contenido en los manuscritos 70, 71 y 72 del fondo español de la Biblioteca Nacional de París: es incompleto al comienzo, le faltan ocho Vidas y el comienzo de la novena; contenía originariamente 39 Vidas, como el ejemplar florentino de la Biblioteca de Santa Croce, en cuatro tomos. Por tanto, Morel-Fatio fue quien hizo

\footnotetext{
${ }^{30}$ Así aparece en el texto de la carta: todo junto; lo respetamos, tal cual es.

${ }^{31}$ Vemos aquí la traducción literal del proemio italiano.

${ }^{32}$ Anotamos aquí como dato importante la observación de Adelino Álvarez al hecho de que algunos autores como Rubió i Lluch, Weis y Sánchez Lasso de la Vega retrasen la fecha de confección de la versión aragonesa al año 1388; según éste, Rubió i Lluch se vio obligado a hacerlo porque hizo coincidir el inicio de la traducción con la llegada a Avignon del "filósofo griego", entre 1384 y 1385; cuestión que quedó invalidada cuando Vives demostró que grandes partes de las Vidas ya habían sido utilizadas en la primera partida de la Grant crónica de Espanya. Vemos, pues, cómo, según Vives, se conforma un terminus ante quem anterior al nombramiento de Juan Fernández de Heredia como Gran Maestre en 1377; el terminus post quem sería entre 1384 y 1385.
} 
un primer estudio de esta cuestión. La supuesta traducción de Heredia (digo supuesta porque, como hemos visto, no es obra suya, sino producto meritorio de su afán de promoción humanística) no sólo ha merecido la atención de los investigadores, sino también que haya sido objeto de diversas tesis doctorales. Así en 1978 Pério leyó en la Sorbona una tesis con el título Études lingüistique des "Vidas de los hombres ilustres", selon les manuscrits de Fray Joan Fernández de Heredia. En 1982 Edward W. Irvine presenta en la universidad de Toronto una tesis titulada La "Vidas de hombres ilustres". Aragonese translation of the lives of Plutarch: A parcial edition. Y no podemos dejar sin nombrar la del propio editor de las $V i$ das Semblantes Adelino Álvarez Rodríguez que en 1981 leyó en la Universidad Complutense una tesis doctoral con el título, Las "Vidas de hombres ilustres" ( $n^{\circ}$ s. 70-72 [del fondo de manuscritos españoles y portugueses] de la Biblioteca Nacional de París. Estudio y edición, donde se editan las Vidas contenidas en los códices parisinos, si bien se tienen en cuenta los cinco códices matritenses que las contienen parcialmente y los códices 7-10 del plúteo XXXVI sin. de la Biblioteca Mediceo-Laurenziana, que contienen la traducción italiana de las Vidas aragonesas. Precisamente Adelino Álvarez Rodríguez en la "Introducción" al volumen I de su edición (2009) dice que se ha servido de los códices 70-72 (=P) del fondo español y portugués de la Biblioteca Nacional de Francia, pero que ha utilizado los códices 10133 (M), 211 (C1), 12367 (C2), 1090 (C3) y 10 34bis de la Biblioteca Nacional de España, así como los códices 7-10 (F) del plúteo XXXVI sin. de la Mediceo-Laurenziana; añade que se ha valido de la recensio de Ziegler (Plutarco, 1964-1973) ${ }^{33}$. Pério transcribe sólo los códices de la Biblioteca Nacional de París y no tiene en cuenta los de la Biblioteca Nacional de Madrid y los códices italianos; Edward W. Irving edita sólo los ochenta y ocho primeros folios de los manuscritos 70-72.

Sobre el por qué de la decisión de Heredia de encargar la versión al aragonés de las Vidas, en mi opinión, lo que le interesaba sobre todo al Gran Maestre era conocer, si no de primera mano, sí por parte de quienes estaban lingüísticamente preparados, cuestiones relacionadas con la gran historia del mundo helénico y con sus grandes personajes que aparecen en las Vidas Paralelas de Plutarco,

\footnotetext{
${ }^{33}$ Se refiere, seguramente, a la edición de K. Ziegler (Bibliotheca Scriptorum Graecorum et Romanorum Teubneriana) cuyo vol. I, fasc. I es del año 1968 y el vol. IV, Indices es de 1980, reed. de la edición teubneriana (desde 1914); cf. también el estudio del mismo K. Ziegler sobre las Vidas: "Plutarch von Chaironeia" RE 21, 1951, cols. 636-692.
} 
como sustrato necesario para su idea de crear una cierta historia universal; tal vez, podríamos añadir, como aparato escénico paradigmático de su propia actividad política, que no es otra cosa que el objetivo declarado por el propio Plutarco a la hora de dar una razón de sus intenciones biográficas y la definición plutarquea de lo que es una Vida (Aem. 1, 1): un "espejo" que le impele a adornar y asemejar su vida a las virtudes de aquellos hombres; una intencionalidad paradigmática, al fin y al cabo, que se transfiere de algún modo al propio Gran Maestre. Sin embargo, a pesar de que no se trata de una traducción directa del texto original, sobre la fidelidad a éste deben hacerse ciertas matizaciones. Según J. S. Lasso de la Vega ${ }^{34}$, es un texto fiel y esa fidelidad se explica porque la versión al griego moderno de Talodiqui "podía ajustarse ceñidamente al texto antiguo, del que, al fin y al cabo, sólo era una "modernización": dicho de otra manera, el griego moderno de aquel tiempo, o sea el bizantino del siglo XIV, no estaba muy lejos, ligüísticamente hablando, de su antecesor el ático del siglo $\mathrm{V}$ a. C. a pesar de los siglos transcurridos; al fin y al cabo el bizantino es una continuación del griego antiguo en su modalidad dialectal ateniense. Luego veremos que, en mi opinión, no es así. Adelino Ávarez Rodríguez (p. XXX) habla de una traducción del "griego popular": "Por el proemio del volgarizzatore", dice, "sabemos que la traducción aragonesa no se hizo directamente del griego clásico, sino a través de una traducción al griego popular"; que, viene a ser lo mismo que, como hemos visto, se dice, y se continúa, en la carta IV de Juan Andrés. Pero debemos hacer algunas matizaciones a esta cuestión. Hoy conocemos por griego popular al nivel lingüístico de la lengua griega actual denominado dimotikí frente al nivel kazerévousa, o lengua pura; por ello debemos andar con cuidado cuando leemos que ha sido traducido al "griego popular"; no hay que olvidar la formación, al parecer, sumamente profunda de los dos traductores alternativos para que no pudieran caer en confusión: el que hizo la versión al supuesto "griego popular" y el que vertió ésta al aragonés. La confusión, creo, viene de la interpretación literal de la carta latina que Coluccio Salutati dirige a Heredia y de la versión italiana de éste. En mi opinión, tendríamos que aplicar aquí, para interpretarlo correctamente, un parámetro opositor: "popular", que traduce al lat. vulgare, vendría a ser el término caracterizado de la oposición griego clásico / griego bizantino, en el sentido de que éste último habría adquirido características distintas al primero y todavía el griego clásico en aquel tiempo era considerado como modelo lingüístico primigenio, y, por tanto, el término no caracterizado de la oposición: "popular" (< lat. vulgare) es determinante lingüístico

\footnotetext{
${ }^{34}$ Art. cit.
} 
de griego bizantino. El problema está en que no se ha conservado la traducción bizantina que sirvió de base para la versión al aragonés, y la teoría sería, hoy por hoy indemostrable, a pesar de que, según Adelino Álvarez, se pueden rastrear ( $\mathrm{p}$. XXX) elementos lingüísticos de la lengua bizantina de los códices de la primera traducción que avalarían una traducción oral intermedia a la operatividad translatora al aragonés, algo así como una traducción simultánea, pero, en mi opinión, no nos llegaría más allá de certificar una pronunciación bizantina del siglo XIV de vocablos clásicos (itacismo, sonorización, etc.), que son equivalentes y continuados en el griego moderno actual. Por tanto, cuando Coluccio Salutati, el traductor al italiano, dice en carta al magnate aragonés: "Ceterum scio quod de greco in grecum vulgare et de hoc in aragonicum Plutarchum - De historia XXXXVIII ducum et virorum illustrium- interpretari feceris", con la expresión grecum (=graecum) vulgare se está refiriendo no a una supuesta lengua griega popular o vulgar, un sermo vulgare, un dimotiki de aquella época y tiempo, sino a la lengua bizantina pura de aquel momento que, en su espejo de corrección, el griego clásico (el del texto griego auténtico de Plutarco), es considerada y visualizada con aditamentos que se desvían de la belleza de la lengua griega clásica escrita por el queronense y por ellos es designada en la traducción latina como vulgare porque no existe en latín otro expediente morfológico adecuado como continente lingüístico para tal nivel semántico; dicho de otro modo: sería un nivel lingüístico bizantino a secas en su forma más pura. Así es como, en mi opinión, debe interpretarse también el "la qual fu translatata di gramatica greca in vulgar greco" del proemio a la edición italiana de las Vidas (cf. infra): vulgare no quiere decir "popular", sino "no clásico", que sería el término caracterizado de la oposición. Además, en la mente lingüística de aquella gente la visión paralela de la oposición entonces imperante lengua latina (=lengua culta) / lengua vulgar (=las derivadas del latín: castellano, aragonés, catalán, francés, etc.), dado que en aquel tiempo la lengua latina era la lengua de comunicación imprescindible, tanto diplomáticamente como literariamente, se transfiere paralelamente a la lengua griega de aquel entonces: lengua clásica griega del texto de Plutarco / lengua griega no clásica (=bizantino del texto de la traducción de Talodiqui). De todos modos, la técnica traductoria imperante de la época, en un esfuerzo por ceñirse a una fidelidad, hace que el autor de la traducción aragonesa conserve los vocablos griegos cuando no encuentra otros en aragonés para verterlos: tal podría ser el caso de uno tan curioso como Squilutafos (Cat. 118v) ${ }^{35}$ : luego lo veremos. Lasso de la Vega (art. cit.) considera que

\footnotetext{
${ }^{35}$ Citado por Adelino Álvarez (p. LXXXV).
} 
su versión es mejor que la posterior de Alfonso Fernández de Palencia (s. XV). Adelino Álvarez, frente a la opinión de Lasso de la Vega y de otros (Juan Andrés, Weis), que unánimamente avalaron su fidelidad, afirma rotundamente (p. CVII) que "está llena de infidelidades". Pero también en esto debemos hacer matizaciones. Comparemos, por ej., el texto griego del principio del cap. 87 con la traducción aragonesa (p. 372 de la edición de Adelino Álvarez) de la Vida de Antonio:

E dexó Antonio de III mulleres fillos VII, de los quales César mató solamente el primero, mas los otros recibió Octavia e nodrió los suyos e de su marido.

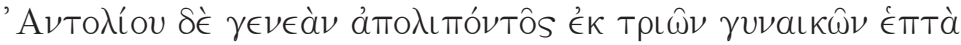

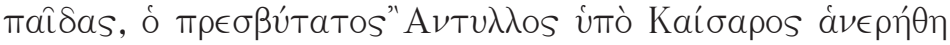

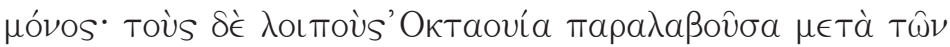
ÉK É
\end{abstract}

En realidad, según el texto auténtico griego de Plutarco, Octavia los crió junto con sus propios hijos (=los de ella misma), no se habla para nada de su marido. El texto griego de Plutarco en realidad dice que "los acogió y los crió junto con los de ella misma": aunque venga a ser lo mismo, no hay ninguna referencia a su marido. Se salta además el nombre del que César mató, ya que el texto griego viene a decir que "el mayor, Antilo, fue el único que fue muerto por César". Aparte de que podría responder a una mecánica de traducción por el sentido, no podemos saber si esos descuidos ya lo estaban en la traducción bizantina, porque no se conserva el texto bizantino. O tal vez, dado que el texto aragonés dispone de "adiciones" ${ }^{36}$, algunas de las cuales actúan a modo de notas aclaratorias equivalentes a las que se colocan en nuestras traducciones a pie de página, como "entró en Pilas, que agora se clama Portojunco (Ages. XVII, 4), habría que atender a lo que se dice en J. Alsina, Literatura griega. Contenido, problemas y métodos (Barcelona, Ariel, 1967, en el capítulo dedicado a la traducción ("VI. Teoría de la traducción", pp. 425444), sería una traducción en cierto sentido parafrástica, supletórica o pariodística (cf. apartad b), p. 428), anticipo de la moda que se impuso por algunos traductores franceses del siglo XVIII. Pero si entendemos que traducir es trasladar el significante de una lengua al significante de otra sin alterar su significado, trasladando además los valores suplementarios, estamos en camino de entender la postura del

\footnotetext{
${ }^{36}$ Cf. Adelino Álvarez p. XCII.
} 
traductor aragonés al enfrentarse a un texto escrito en una lengua que, por más que es griega, está algo lejano del texto original plutarqueo, el cual ya de por sí debía tener su personalidad propia interpretativa. Resulta difícil pensar, como hace Lasso de la Vega, que, como la lengua posterior en el tiempo, el bizantino, es derivada del griego clásico, ello origina necesariamente fidelidad en la traducción. Sería lo mismo que si en lengua castellana se hiciera una traducción del poema del Mío Cid, con el supuesto esfuerzo del traductor en "actualizar lingüísticamente" el texto en su esfuerzo para hacerlo entendible.

Queda claro, por tanto, que hubo dos traducciones, una basada sobre la otra: la aragonesa en un texto bizantino que no se conserva, y la bizantina, no conservada, en el original griego de Plutarco. La determinación de fidelidad al texto queda, en consecuencia, limitada al texto aragonés con respecto al texto bizantino. No podemos decir que es fiel al texto original de Plutarco, puesto que la traducción del tal Nicolás (o Nicolaus) no se hizo sobre éste, sino sobre otra traducción; en todo caso diríamos que es o no lo es fiel en relación con ese texto bizantino al que llaman, incluido Adelino Álvarez, "vulgar"; pero habría que determinar antes si ese texto "vulgar" es fiel al texto de Plutarco; pero, como no se sabe nada de él, sólo por lo que nos dice el proemio de Salutati, ni siquiera eso: nos quedamos en nada. Por tanto, el texto aragonés ni es fiel ni no lo es al texto original de Plutarco. No podemos afirmar ni negar nada. Pero tampoco podemos afirmar ni negar nada de la fidelidad del texto aragonés al texto bizantino, porque, como hemos dicho antes, éste no nos ha llegado. Nos queda sólo contentarnos con el texto aragonés y el texto de Plutarco y contrastar ambos, dejando peligrosamente un eslabón suelto. Sólo nos quedamos con una cosa firme: no fue su autor Juan Fernández de Heredia, por más que por inercia se suele afirmar, sino su insigne promotor. Por tanto, se puede decir que sus "supuestas" traducciones y compilaciones no son sólo obra de un humanista precoz, sino la de un inteligente bibliófilo apasionado por cualquier aspecto de la historia universal, un promotor cultural de gran envergadura, como diríamos hoy, y esto lo hemos de tener muy en cuenta en sus Vidas Semblantes. En todo caso, tenemos aquí un inapreciable texto en lengua aragonesa, del cual indudablemente se beneficiarán los romanistas en sus investigaciones.

Juan Fernández de Heredia viajó a Rodas en 1354-55 como enviado papal junto a Raimundo Berenguer y Pedro de Cornillán, pero fue durante su segunda estancia entre 1379-82 cuando organizó la producción de su futura obra histórica. E1 encargo de las traducciones de textos griegos recayó en un primer momento en el salonicense ya citado Demetrio Talodiqui que aparece mencionado en el proemio 
de la versión italiana de Salutati; el tal Talodiqui, o Calodiqui, tenía por cometido traducir del griego clásico al griego vulgar (entiéndase, como hemos dicho, el bizantino), mientras que un segundo personaje, Nicolás, obispo de Adrianópolis, ya mencionado, trasladaba el texto del griego vulgar al aragonés; el proemio italiano al que nos hemos referido antes dice así:

Cronica de Plutarco famoso historial greco, la qual fu translatata di gramatica greca in vulgar greco in Rodi per uno philosopho grecco chiamato Dimitri Talodiqui, e di greco fu translatata in aragonese per un freire predicatore vispo di Ludervopoli, molto sofficente cherico in diverse scienze, e grande historiale, e experto in diverse lingue.

Sobre la cuestión de si el tal Nicolás, o Nicolaus, tenía conocimientos de la lengua aragonesa suficientes como para emprender una traducción, por ser, tal como se especifica en el proemio de la edición italiana, "experto en diversas lenguas", o si sólo alcanzaba a ser una "lengua de lectura", y hubo necesidad de recurrir a una cierta "aduana de la corrección" remito a Adelino Álvarez ("Introducción", p. CXLI). Por otra parte, J. S. Lasso de la $\mathrm{Vega}^{37}$ pone atención a los préstamos lingüísticos aragoneses (aragonesismos) que se pueden detectar en la traducción del texto italiano sobre el texto aragonés; para este autor la versión aragonesa de los códices de París es la de Heredia pues puede comprobarse por el paralelismos de los textos: el texto italiano sigue casi al pie de la letra al texto aragonés. Para esta cuestión remito Adelino Álvarez Rodríguez, que hace un estudio pormenorizado de los elementos catalanes, galorománicos, latinos, griegos e italianos, con sus correspondientes préstamos morfológicos, así como de las causas de las numerosas omisiones y reduciones ${ }^{38}$; lo mismo con respecto a los errores ${ }^{39}$. El

\footnotetext{
${ }^{37}$ Art. cit., p. 462.

${ }^{38}$ Que, resumidamente, según el autor, son las siguientes: a) pasajes sexualmente escabrosos; b) falta de comprensión del original; c) poco interés otorgado al pasaje; d) interés por llegar cuanto antes al final de la tarea.

${ }^{39}$ Según él, por las siguientes causas: a) la más frecuente: desconocimiento del significado de los términos; b) dificultad gramatical (incomprensión de piezas por causa de la sintaxis): así se entiende

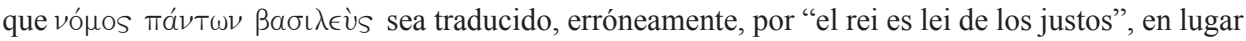
de "la ley es rey de todos", que es la norma que presidió en los siglos V y IV a. C la constitución ateniense, en versión aristotélica, de que el ciudadano sólo tiene por encima la ley; c) pasajes oscuros: desconocimiento de su contexto cultural o histórico.
} 
traductor bizantino fue el ya mencionado Talodiqui, que era philosopho y escribano natural de Tesalónica ${ }^{40}$. Los documentos certifican que Juan Fernández de Heredia concedió a Talodiqui a perpetuidad una escribanía en Rodas y el 12 de marzo de 1382 le autorizó a apoderarse de los códices de un tal Gavidiotti, que habían pertenecido al hermano de éste; uno de éstos, según Lutrell, podría ser el de las Vidas. El segundo traductor utilizado por Juan Fernández de Heredia fue, como hemos dicho, el dominico Nicolás, obispo de Drenópolis (=Adrianópolis, en Etolia), que había servido de traductor en el viaje de Juan V Paleólogo a Roma (a. 1369). De 1380 a 1384 se encontraba en Rodas, ejerciendo de vicario del arzobispo. De 1384 a 1386 vivió en Avignon, en donde tradujo los textos reunidos por Heredia. La traducción al aragonés de las Vidas Paralelas de Plutarco fue utilizada en sus obras la Grant Crónica de los Conquiridores y en la Grant Crónica de Espanya. Adelino Álvarez Rodríguez plantea una cuestión importante: si Calodiqui (o Talodiqui) se limitó a traducir oralmente o si dio forma escrita a sus traducción; favorece la primera, la versión oral, según él, el hecho de que no se conserva la versión bizantina intermedia; pero, en mi opinión, también podría haber sucedido que la versión bizantina escrita hubiera desaparecido por razones diversas: el paso del tiempo, o que no se le dio la importancia que tenía y que sólo fuera un borrador, punto de partida para una traducción a una lengua romance: ello sin contar, en mi opinión, que, si se defiende la traducción oral, entonces el traductor bizantino y el traductor aragonés forzosamente tendrían que estar muy coordinados simultáneamente en su operación translatoria, y yo no me imagino, dada la extensión de la obra de Plutarco, que pudieran hacerlo, hora a hora, día a día, mes a mes, año a año, durante mucho tiempo: eso que hoy denominamos traducción simultánea, pero con un gasto de tiempo incré́ble. Cuestiones de itacismos del griego bizantino (fenómeno fonético también del griego moderno), como dímo por dêmos, tampoco avalan esa supuesta operatividad oral: no había entonces reglas de transcripción, que nosotros sí que tenemos para el castellano, como son, como mínimo, por ejemplo, la que en su día publicó Manuel Fernández Galiano (La transcripción clásica de los nombres propios griegos, Madrid, $\mathrm{Pu}-$ blicaciones de la S.E.E.C., 1961); la lengua catalana actual tiene otra, la de Joan Alberich y Monserrat Ros con la colaboración de Joan Morera, La transcripció dels noms propis grecs i llatins, Barcelona, Enciclopedia Catalana, 1993); y cada lengua europea, las suyas. Tal es el caso de Squilutafos (Cat. 118v), "sepultura de

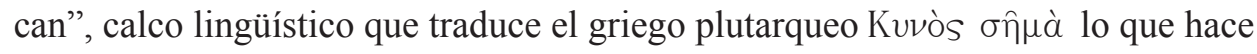

\footnotetext{
${ }^{40}$ Cf. n. 5 .
} 
el traductor aragonés es simplemente transliterar (tal vez por desconocimiento del vocablo) la versión bizantina del vocablo con otro vocablo compuesto equivalente, del cual su primer componente también lo tenemos en griego moderno dimotiki en forma neutra, Tò $\sigma \kappa v \lambda i ́$, forma derivada del griego clásico diminutivo Tò $\sigma \kappa v$ -

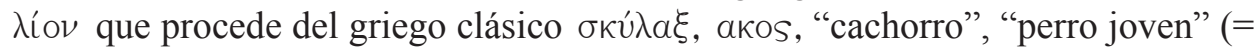
en gr. kazerévousa); el segundo término del compuesto bizantino, táфos traduce

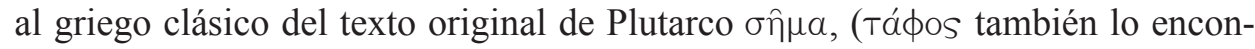
tramos en griego clásico): si nosotros lo tuviéramos que transcribir lo haríamos con -ph- (táphos). Además, el primer componente lo transcribiríamos, si se tratara del griego clásico, siguiendo las normas estrictas de transcripción, con - $y$ - griega: skylou. Pero, naturalmente, en esa transliteración se transfiere la pronunciación itacista de la versión bizantina, tal como ocurre en griego moderno, donde $\mathrm{ol}, \mathrm{\epsilon l}$, $v, \eta$, fonéticamente pasan a una pronunciación itacista $-i-$. El traductor, por tanto, lo que hace es simplemente transcribir la pronunciación actual del componente que la versión bizantina, en un proceso de actualización, ha elegido para los dos vocablos del original de Plutarco, manteniendo la - $f$ - (ya se pronunciaba así la - $\phi-$, igual que hoy en griego moderno); podría haber dado en aragonés su significado; sin embargo ha preferido transliterar el término bizantino, tal vez por desconocimiento, sin más, del contenido semántico del vocablo ${ }^{41}$ o por alguna otra razón que desconocemos. Por otra parte, el humanista Coluccio Salutati consiguió una copia de la versión aragonesa antes de 1388 y sobre ella se realizó una versión italiana, cuyo proemio ha proporcionado la valiosa información ya transcrita antes sobre la gestación del proceso. No vamos a entrar si el traductor era catalán, o aragonés (= tesis de Lutrell, 1960). Sí debemos decir que la edición crítica de Adelino Álvarez de 2009 (Plutarco. Vidas Semblantes. Versión aragonesa de las Vidas Paralelas patrocinada por Juan Fernández de Heredia, Zaragoza, Prensas Universitarias de Zaragoza, Departamento de Educación, cultura y Deporte del Gobierno de Aragón; Huesca, Instituto de Estudios Altoaragoneses; Teruel, Instituto de Estudios Turolenses, 2009, 2 vols.), nos permite tener a mano un instrumento primordial inapreciable.

Los plutarquistas estamos acostumbrados a leer en la Vidas primero la vida de Teseo y, a continuación, la de Rómulo, más la $\sigma \psi \gamma \kappa \rho ́ \sigma \in \iota \sigma$ (comparaciones) correspondientes; luego la de Licurgo y Numa, los dos grandes legisladores, tal como leemos en la edición de Ziegler de la Biblioteca Teuberiana (vol. I). La

\footnotetext{
${ }^{41}$ Que es la opinión de Adelino Álvarez Rodríguez (p. CXXIII).
} 
traducción de Juan Fernández de Heredia, en la edición de Adelino Ávarez Rodríguez, comienza con la de Sertorio, sigue la de Eumenes (Eumenio en aragonés) y, a continuación la ó $\gamma \kappa \rho \iota \sigma \iota \sigma$ de ambos (vol. I, p. 67). Pero no se ha de olvidar que Licurgo y Numa son una de las 9 Vidas que faltan. Sabemos que Plutarco llegó a escribir unas sesenta y siete Vidas (otros dicen 68 o 69), de las cuales sólo nos han 1legado, como hemos dicho, cincuenta: el proemio de la traducción italiana de Salutati da una división de la obra en 48 Vidas (veinticuatro griegos más veinticuatro romanos); pero sólo se tradujeron al aragonés 39 (en el proemio se dice quadraginta octo ducum et viroum illustrium); faltan las que no van emparejadas con sus correspondientes romanas (Arato, Artajerje y Galba y Otón) ${ }^{42}$, más las de Agis y Cleómenes, las de Tiberio y Cayo Graco, y las de Numa y Licurgo; también la Vida de Arístides, la ớxpı $\iota \iota \sigma$ de Catón el Mayor. Las Vidas escritas por Plutarco están emparejadas en la recensión bipartita comenzando por la Vida de Teseo y terminando en la Vida de Arato $^{43}$. La recensio tripartita coincide en su orden con la de Planudes (cod. Marc. 481): Teseo / Rómulo; Solón / Publícola /, Temístocles / Camilo, etc.

El aragonés de la traducción es un aragonés castellanizado (el término es de Vives, 1927, p. 32) y en cierto modo, aunque en poca medida, catalanizado; Adelino Álvarez Rodríguez en su "Introducción" da nota suficiente de ello y a ella, en ahorro de tiempo, remito. Sobre los catalanismos, léase al respecto un interesante trabajo de Antoni M. Badía i Margarit: «Algunas notas sobre la lengua de Fernández de Heredia», Rev. de Filol. Esp., 28 (1944), 177-89. Léase también referente a este tema José Vives, Juan Fernández de Heredia, Gran Maestre de Rodas. Vida,

\footnotetext{
${ }^{42}$ En la carta de Salutati a Heredia se dice: Habeo quidem rubricarum maximam partem, que hace pensar que no se llegaron a traducir todas.

${ }^{43}$ Sería como sigue: 1. Teseo y Romulo; 2. Licurgo y Numa; 3. Temistocles y Camilo; 4. Solón y Publícola; 5. Pericles y Fabio Máximo; 6. Alcibiades y Marco Coriolano; 7. Foción y Catón; 8. Agis y Cleómenes - Tiberio y Gaio Gracco; 9. Timoleón y Paulo Emilio; 10. Eumenes y Sertorio; 11. Aristides y Catón; 12. Pelópida y Marcelo; 13. Lisandro y Sila; 14. Pirro y Mario; 15. Filopémenes y Tito; 16. Nicias y Crasso; 17. Cimón y Lúculo; 18. Dion y Bruto; 19. Agesilao y Pompeyo; 20. Alejandro y César; 21. Demóstene y Cicerón; 22. Demetrio y Antonio; 23. Vidas sin pareja son: 1. Arato y Artajerje; 2. Galba; 3. Otón. Vidas perdidas son: 1. Vida de Augusto; 2. Tiberio; 3. Escipión Africano; 4 Claudio; 5 Nerón; 6. Cayo César; 7. Vitelio; 8. Vida de Heracles; 9. Vida de Hesíodo; 10. Vida de Píndaro; 11. Vida de Crates; 12. Vida de Crates; 13. Daifanto (Defanto); 14. Aristómenes; 15 Arato. La versión de Heredia no sigue el orden de la recensión bipartita; algunas siguen la recensión tripartita (Dión-Bruto; P. Emilio-Timoleón; Sertorio-Eumenes; Filopemen-T. Q. Flaminio; y Pelópidas-Marcelo). Para más detalles, cf. Adelino Álvarez, op. cit.
} 
Obras, Formas Dialectales, Barcelona, Biblioteca Histórica de la Biblioteca Balmes, 1927, 2 vols. Se ha llegado a cuestionar la nacionalidad del traductor y sobre que probablemente era catalán ${ }^{44}$. Es interesante la descripción que hace Badía i Margarit de algunos hechos; sólo indico algunos: por ejemplo, su declaración de que la grafía de la lengua medieval es constantemente irregular y la aseveración de irregularidades gráficas mucho más difíciles de controlar debidas a la poca cultura de los copistas, a distracciones ( $\mathrm{p}$. ejemplo ha preposición por $a$ ), formas de artículo con h (hun por un), etc. A pesar del tiempo transcurrido es un trabajo útil, por más que su espectro investigador se amplia a otras obras del Gran Maestre (Emperadores, Conquiridores, etc.). Badía i Margarit expresa de buen principio su intención de que, aunque muchas de las construcciones señaladas son comunes a todos los dominios lingüísticos peninsulares, le interesa destacar su relación con el catalán especialmente, como expresión de tantas concomitancias culturales y de historia política como unen a los dos pueblos. Por otra parte, Adelino Álvarez Rodríguez (p. LXXXII) añade la cantidad enorme de vocablos catalanes que contiene, por ej. comiat (despedida), aleujament (= cat. mod. allunyament) (alejamiento), arreu (dondequiera), etc.

Para terminar, he aquí, resumidos, otros hechos a destacar:

1. Las sýgkríseis son anunciadas: p. ej. p. 374: Aquí face comparar el actor de Antonio e de Dimitrio.

2. Cada una de la Vidas tiene indicaciones (no en texto griego) de la situación ordinal de ella: p. ej. Aquí comienza el proemio de Dimitrio Poliorquite; e es el quinto decimo libro.

3. No hay división en capítulos, si bien están indicados en números romanos entre medio del texto. Sí que hay resúmenes explicativos: Como los de Seleuco vencieron e mataron a Antígono en batalla (Dem. p. 245); Cómo Mario metió división entre los gentiles hombres e Saturnino; e de las cosas que después se siguieron (Mar. p. 472).

4. Fenómenos de itacismos: Demetrio, se convierte e Dimitrio. Dimitrio Poliorquite por Demetrio Poliorcetes. Ípiro por Epiro. Cipión por Cepión; Mitridati,

\footnotetext{
${ }^{44}$ Para más detalles remito a Adelino Álvarez Rodríguez p. XVII de su "Introducción”.
} 
por Mitrídates; Philopimi por Filpemen, Pelopidi por Pelópidas, Agisilao por Agesilao, Temistocli ( $\sin t h$, que en cambio sí posee Theseo)

5. Algunos nombres son calcados literalmente del texto griego, incluso con su acento original: Kátlo (Cátulo); Marco Cato (Catón). Igual pasa con Cícero por Cicerón; Quimon (Cimón); Niquías (Nicias); Crasso (con dos ss); Lissandro (con dos $s s$ );

6. Otros con transcripciones extrañas: Demostenin; Poplicolo (Publícola); Cherróniso (Quersoneso: con ch); Alcibiados (frente, curiosamente, a Niquías); Ércules ( $\sin h)$; quimbrios (cimbrios); Teópompo ( $\sin t h)$, que sí hemos visto en Theseo.

7. A veces faltan capítulos enteros; tal puede comprobarse en el "Apéndice a la Vida de César", donde se pasa del cap. 44 (batalla de Pompeyo y César) al cap. 60, donde se explica que el odio contra César procedía de su deseo de reinar.

\section{Conclusión}

Como colofón de todo, y como lo más destacable, en mi opinión, es que, si bien la versión en aragonés es, entre otras cosas, un documento inapreciable para los filólogos, tanto para los helenistas como, muy especialmente, para los romanistas y, sobre todo, los especialistas en lengua aragonesa, no podemos asegurar en modo alguno la fidelidad de su traducción; tampoco negarla. Que hoy dispongamos de una edición reciente (2009), moderna y bien cuidada del texto aragonés, es algo muy importante. Que fuera Talodiqui el que proporcionara la versión bizantina al traductor Nicolaus (o Nicolás), y que esa versión bizantina desgraciadamente no haya llegado a nosotros, tal vez no es lo más importante. Sí lo es comprobar hasta qué punto Plutarco atraviesa las fronteras del tiempo en un momento de gran efervescencia humanística, y, gracias a la sensibilidad y empeño por los temas del mundo clásico de un gran hombre de Estado del siglo XIV, Juan Fernández de Heredia, llega hasta nuestros días en un documento valioso, que, a la vez, nos aporta elementos que abren un panorama investigador inestimable sobre la lengua aragonesa. 


\section{Bibliografía}

Alberich, J. - Ros, M., La transcripció dels noms propis grecs i llatins, Barcelona, Enciclopedia Catalana, 1993 (con la colaboración de Joana Morera).

Alsina, J., Literatura griega. Contenido, problemas y métodos (Barcelona, Ariel, 1967, en el capítulo dedicado a la traducción ("VI. Teoría de la traducción", pp. 425-444).

Alvar, M., El dialecte aragonès, Madrid, Gredos, 1953.

Estudios sobre el dialecto aragonés, Zaragoza, Institución Fernando el Católico, 1973, 1987.

Álvarez Rodríguez, A., "Juan Fernández de Heredia y las traducciones del griego medieval al aragonés”, Eryteia 7, 1986, 113-131.

Tucídides. Discursos de la guerra del Peloponeso. Versión aragonesa de la Historia de la guerra del Peloponeso, patrocinada por Juan Fernández de Heredia (ed.), Zaragoza, Larumbe, 2007.

Plutarco. Vidas semblantes I-II. Versión aragonesa de las Vidas Paralelas de Plutarco patrocinada por Fernández de Heredia, Zaragoza, Larumbe, 2009.

Badía i Margarit, M.: «Algunas notas sobre la lengua de Fernández de Heredia», Rev. de Filol. Esp. 28, 1944, 177-89.

Cacho Blecua, J. M., El gran maestre Juan Fernández de Heredia, Zaragoza, Caja de Ahorro de la Inmaculada de Aragón, 1977.

"Introducción a la obra literaria de Juan Fernández de Heredia", en J. M. ENGUITA (ed.), 1996, 171-195.

Cerezo Magán, M. "Plutarco en la encrucijada greco-romana", Scriptura 1, 1986, Universidad de Lleida, 117-123.

"Plutarco y Polibio. Problemática de un bilingüismo activo", Sintagma 4, 1992, Universidad de Lleida, 15-21. 
“La superstición según Plutarco de Queronea, ¿otra forma de religión?”, Actas del III Simposio Español sobre Plutarco, Madrid, Ediciones Clásicas, 1994, 157-168.

Plutarco. Virtudes y vicios de sus héroes biográficos, Universidad de Lleida, col. "Estudi General", 1997.

"Embriaguez y vida disoluta en las Vidas", comunicación al VI Simposio Español sobre Plutarco, organizado por la Sociedad Española de Plutarquistas y la International Plutarch Society (IPS), dentre del tema "Plutarco, Dioniso y el Vino", celebrado en la Universidad de Cádiz (14-16 de mayo de 1998) (publicado en les Actas sobre el tema Plutarco, Dioniso y el vino, Madrid, Ediciones Clásicas, 1999, 171-180.

"Paideia plutarquea diacrónica en la frontera del tiempo: El Plutarco extremeño de Nicolás Díaz y Pérez", VIII Simposio Internacional de la Sociedad Española de Plutarquistas (IPS: International Plutarch Society), Universitat de Barcelona, 2003, 681-692.

"Sobre la expedició de catalans a Grècia" Ataraxia 1, 1966, pp. 16-17; (Ataraxia es una revista de divulgación cultural del Instituto de bachillerato Joan Oró de Lleida).

De Riquer Morera, M., "Medievalismo y humanismo en la Corona de Aragón a finales del siglo XIV", VIII Congreso de la Historia de la corona de Aragón, t. II, vol. I, Valencia, sucesor de Vives Mora, 1969, 221-235.

Egido, A. Y Enguita, J. M. (eds.), Juan Fernández de Heredia y su época, IV curso sobre lengua y literatura de Aragón, Zaragoza, Institución Fernando el Católico, Zaragoza, 1991; coord. por Tomás Buesa Oliver, Aurora Egido.

Enguita, J. M. (ed.), I Curso sobre lengua y literatura de Aragón (Edad Media), Zaragoza, Institución Fernando el Católico 1991; coord. por Tomás Buesa Oliver, Aurora Egido.

II Curso sobre lengua y literatura de Aragón (Siglo de Oro), Zaragoza, Institución Fernando el Católico, 1993; coordinado por Aurora Egido, Tomás Buesa Oliver, José María Enguita Utrilla. 
III Curso sobre lengua y literatura de Aragón (siglos XVIII-XX), Zaragoza, Institución Fernando el Católico, 1994; coord. por José María Enguita Utrilla.

IV Curso sobre lengua y literatura de Aragón (Juan Fernández de Heredia y su época), Zaragoza, Institución Fernando el Católico, 1997; coord. por Aurora Egido, José María Enguita Utrilla.

V Curso sobre lengua y literatura de Aragón (Localismo, costumbrismo y literatura popular en Aragón), Zaragoza, 1999; coord. por José Carlos Mainer Baqué, José María Enguita Utrilla.

VI Curso sobre lengua y literatura de Aragón (100 años de Filología en Aragón), Zaragoza, 2006; coord. por José Carlos Mainer Baqué, José María Enguita Utrilla.

VII Curso sobre lengua y literatura de Aragón (Los pasos del solitario: (dos cursos sobre Ramón J. Sender en su Centenario), Zaragoza, 2004; coord. por José Carlos Mainer Baqué, Javier Delgado, José María Enguita Utrilla.

Fernánez Galiano, M., La transcripción clásica de los nombres propios griegos, Madrid, Publicaciones de la S.E.E.C., 1961.

Giménez López, E., Bolonia, Florencia, Roma. Cartas familiares I Juan Andrés Morell, Publicaciones de la Universidad de Alicante, 2004, 559 págs.

Lasso De La Vega, J. S., Traducciones españolas de las "Vidas" de Plutarco" EClás. 35, 6, 1962, 451-514.

López Molina, L., Tucidides Romanceado en el siglo XIV, Madrid, Anejos de BRAE, 1960.

Luttrell, A., "Actividades Económicas de los Hospitalarios de Rodas en el Mediterráneo Occidental durante el s. XIV", VI Congreso de Historia de la Corona de Aragón, Madrid, 1959, 175-83.

"Interessi Fiorentini nell'Economia e nella Politica dei Cavalieri Ospedalieri di Rodi nel Trecento", Annali della Scuola Normale Superiore di Pisa 28, 1959, 317-26. 
"Greek Histories Translated for Juan Fernández de Heredia, Master of Rhodes”, 1377-1396", Speculum 35, 1960, 401-407.

"The Aragonese Crown and The Knights Hospitallers of Rhodes: 1291-1350", The English Historical Review, 76 (1961), 1-19.

Nieto Soria, J. M., "Las inquietudes historiográficas del Gran Maestre hospitalario Juan Fernández de Heredia (m. 1396): una aproximación de conjunto". En La España medieval 22, 1999, 187-211.

Plutarc, Vides Paral·lelae, Barcelona, 1926-1959, trad. de Carles Riba.

Plutarchi, Vitae Parallelae, Lindskog, C. L.- Ziegler, (Bibliotheca Scriptorum Graecorum et Romanorum Teubneriana) cuyo vol. I, fasc. I es del año 1968 y el vol. IV, Indices es de 1980; reed. de la edición teubneriana (desde 1914).

Plutarco, Vidas Paralelas, Madrid, Espasa Calpe, 1948-1952, trad. de Ranz Romanillos.

Plutarque, Les Vies Paralleles, París, Assoc. Guill. Budé (desde 1957; el "Índice" en el vol. XVI).

Pottier, B., "L'Evolution de la langue aragonnaise à la fin du Moyen Âge", Bull. Hispanique 54, 1952, 185-199.

Rubió i Lluch, A., Documents per l'història de la cultura catalana migeval, Barcelona, IEC, 1908-1921.

Vives, J., Juan Fernández de Heredia, Gran Maestre de Rodas. Vida, Obras, Formas Dialectales, Barcelona, Biblioteca Histórica de la Biblioteca Balmes, Serie I, vol. II, 1927, 2.

Ziegler, K., "Plutarch von Chaironeia" RE 21, 1951, cols. 636-692. 
Zurita. J., ${ }^{45}$ Anales de la Corona de Aragón (1562-1580) (con múltiples referencias a nuestro autor).

${ }^{45}$ Nació Jerónimo Zurita y Castro en Zaragoza en 1512 y murió en 1580, poco después de la publicación del último volumen de sus Anales. En Alcalá de Henares estudió retórica, latín y griego. Aprendió, además otras lenguas modernas, como el francés, el italiano, el portugués y el catalán. En 1530, y gracias a la influencia de su padre Miguel de Zurita, que fue médico de Fernando el Católico y Carlos I, consiguió el puesto de magistrado de la ciudad de Barbastro y continuo de la Casa Real, para, poco más tarde, ser nombrado baile de Huesca. En 1537 fue nombrado asistente-secretario de la Inquisición al servicio del cardenal Juan Tavera, que desempeñaba los cargos de miembro del Consejo de Estado, inquisidor general y arzobispo de Toledo. En 1548 fue nombrado cronista del Reino de Aragón y en 1566 Felipe II lo nombra secretario para el concilio de la Inquisición, y secretario de su Consejo y Cámara, delegando en él todos los asuntos de suficiente importancia como para requerir la firma del rey. Zurita obtiene una sinecura en Zaragoza y renuncia a sus anteriores cargos el 21 de enero de 1571 para dedicarse por completo a la composición de sus Anales de la Corona de Aragón (1562-1580); es la magna obra de Jerónimo de Zurita, en la que trabajó durante treinta años. En ella historia los sucesos de Aragón en orden cronológico desde el periodo islámico hasta el reinado de Fernando el Católico; el primer tomo aparece en 1562. Vivió para ver el último volumen publicado en Zaragoza el 22 de abril de 1580. Muere el 3 de noviembre de ese mismo año. 